Etnográfica

Revista do Centro em Rede de Investigação em

Antropologia

vol. $13(2) \mid 2009$

Vol. $13(2)$

\title{
Daniel Seabra Lopes, Deriva Cigana: Um Estudo Etnógrafico sobre os Ciganos de Lisboa | Ruy Llera Blanes, Os Aleluias: Ciganos Evangélicos e Música
}

\section{Micol Brazzabeni}

\section{(2) OpenEdition}

Journals

\section{Edição electrónica}

URL: https://journals.openedition.org/etnografica/1183

DOI: 10.4000/etnografica. 1183

ISSN: 2182-2891

\section{Editora}

Centro em Rede de Investigação em Antropologia

Edição impressa

Data de publição: 1 novembro 2009

Paginação: 488-491

ISSN: 0873-6561

\section{Refêrencia eletrónica}

Micol Brazzabeni, «Daniel Seabra Lopes, Deriva Cigana: Um Estudo Etnógrafico sobre os Ciganos de Lisboa | Ruy Llera Blanes, Os Aleluias: Ciganos Evangélicos e Música», Etnográfica [Online], vol. 13 (2) | 2009, posto online no dia 16 maio 2012, consultado o 12 fevereiro 2022. URL: http://

journals.openedition.org/etnografica/1183 ; DOI: https://doi.org/10.4000/etnografica.1183

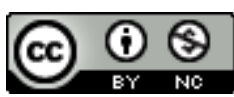

Etnográfica is licensed under a Creative Commons Attribution-NonCommercial 4.0 International License. 
Daniel Seabra Lopes

\section{DERIVA CIGANA: UM ESTUDO ETNOGRÁFICO SOBRE OS CIGANOS DE LISBOA}

Lisboa, Imprensa de Ciências Sociais, 2008, 410 páginas.

Ruy Llera Blanes

OS ALELUIAS: CIGANOS EVANGÉLICOS E MÚSICA

Lisboa, Imprensa de Ciências Sociais, 2008, 260 páginas.

As duas recém-publicadas monografias em consideração são o resultado do trabalho de investigação de dois antropólogos portugueses, Daniel Seabra Lopes e Ruy Llera Blanes, cada uma dedicada à pesquisa no âmbito de projectos de doutoramento. A razão pela qual os dois volumes estão a ser apresentados em conjunto não depende somente da simultaneidade da sua saída no mercado editorial, mas sobretudo da suposta pertença a uma área específica do domínio científico antropológico, relativa aos estudos das comunidades ciganas. Todavia, os textos distanciam-se notavelmente um do outro, quer pelos objectos e sujeitos do estudo, quer pela postura metodológica e epistemológica adoptada pelos dois autores para tematizar, discutir e desenvolver as pesquisas - diferenças que sobressaem e que se revelam estimuladoras de análise crítica.

Deriva Cigana de Daniel Seabra Lopes apresenta-se como uma monografia etnográfica de matriz clássica, se considerarmos, para além da declaração de intentos do autor, o estilo organizativo e argumentativo holista proposto ao longo do texto, que denota a vontade de abordar de forma abrangente quase todos os aspectos "culturais" característicos de uma específica comunidade cigana residente num bairro social de Lisboa. O autor estrutura o discurso em quatro capítulos, cada um centrado na descrição daquilo a que chama "impressões etnográficas"; para cada uma destas propostas interpretativas apresenta e discute pequenos excertos da vida quotidiana de algumas famílias ciganas com as quais o investigador manteve relações ao longo de quinze meses de visitas regulares ao terreno. No primeiro capítulo, "Um passo atrás no tempo", discutem-se conceitos como os de anacronismo, não-simultaneidade, desfasamento e extemporaneidade, aos quais os ciganos estariam associados por razões de "inserção histórica no universo camponês católico" (p. 114); a "Introversão" do segundo capítulo sugere que o mundo dos ciganos seja lido como "claramente delimitado, enconchado, cerrado e, como tal, pouco permeável a certas influências inovadoras que o circundam" (p. 117), assumindo-a como fenómeno performativo; em "Lassidão, desagregação e vazio" o autor pretende esclarecer como estas impressões não são necessariamente "falhas" ou "faltas" do sistema social cigano, mas a assunção por parte deste de uma "posição oblíqua" em relação ao meio social envolvente (pp. 278-280), com vista à preservação da autonomia. Finalmente, o quarto capítulo, "As derivas", analisa criticamente a relação entre a acção "normalizadora" das instituições locais e as tácticas adaptativas dos ciganos.

Vale a pena sublinhar que o diálogo com uma ampla literatura antropológica actual (trabalhos de Paloma Gay y Blasco, Judith Okely, Caterina Pasqualino, Leonardo Piasere, Teresa San Román, Michael Stewart, Patrick Williams) é assertivo e constante, embora o teor argumentativo se revele frequentemente próximo de uma análise sociológica - curiosamente, este livro surge na colecção de sociologia. Talvez decorrente do estilo da escrita, o texto apresenta uma estruturação recorrente, na qual relatos do quotidiano, deduzidos da observação no 
terreno, servem de justificação à discussão teórica que, por sua vez, aponta para eixos temáticos tópicos de uma antropologia que se serve de conceitos construídos fora da comunidade: o patriarcado, o machismo, a virgindade das mulheres, a violência, a tradição e o atraso (cf. David Lagunas, Los Tres Cromosomas: Modernidade, Identidad y Parentesco entre los Gitanos Catalanes, 2005). De resto, o autor está consciente de que o terreno epistemológico no qual se desenvolve a análise é escorregadio; na introdução e na conclusão é evidente a necessidade de tornar claras algumas afirmações ambíguas e que parecem querer desafiar a ideia de que, necessariamente, o antropólogo deva experimentar empatia, ou pelo menos o tente, com os seus interlocutores.

Esta experiência etnográfica revela, talvez de uma forma mais evidente, as dificuldades de imersão no contexto e de incorporação do processo de conhecimento (cf. Judith Okely, The Travellers-Gypsies, 1983; Leonardo Piasere, Un Mondo di Mondi, 1999; Patrick Williams, Nous, on n'en parle pas, 1993). Não é este o lugar para debatermos sobre etnografias bem-sucedidas ou fracassadas, embora a antropologia esteja carente de textos em que os próprios antropólogos reflictam sobre o eventual insucesso das pesquisas de terreno (cf. Piasere, acima referido). Contudo é cientificamente desejável que uma monografia etnográfica produza um conhecimento que nos aproxime das visões do mundo do grupo estudado e que nos ofereça uma análise qualitativa sobre as categorias, estruturas sociais, interpretações, cosmologias e teorias "émicas", que se confronte com a construção interna dos significados e não tanto com uma procura, por parte do antropólogo, de uma coerência entre o seu discurso teórico e as "impressões" pessoais dispersas e logo costuradas. De facto, reflexividade e subjectividade são processos distintos da proposta de aproximação "impressionista" na construção de conhecimento etnográfico. Aliás, esta perspectiva é ambiguamente definida pelo autor (pp. 35-36), deixando frequentemente desnorteado o leitor relativamente à discussão sobre certo tipo de conceitos ou inferências problemáticas, entre outras a questão do anacronismo e da não-simultaneidade temporal dos ciganos (pp. 44-45).

Sublinhe-se, entretanto, que o autor demonstra evidente honestidade intelectual ao pôr o seu percurso interpretativo constantemente em diálogo com outras etnografias sobre comunidades ciganas, mas, ao fazê-lo, sugere também uma leitura oscilante e ambígua de um ponto de vista teórico e interpretativo. Se, por um lado, se distancia de abordagens em que os sujeitos são folclorizados, cristalizados, essencializados culturalmente, ao mesmo tempo parece demorar-se a detectar eventuais "traços" ainda que explicite não serem necessariamente negativos ou não ter ambições de generalização mas sim de comparabilidade - e a "fixar" e "forçar" dentro de categorias "éticas" pouco flexíveis, e que precisariam então ser mais discutidas, os ciganos do bairro estudado e de Lisboa, pelo que a criatividade da comunidade parece desaparecer.

De um outro modo, a abordagem teórica, o objecto de estudo e a metodologia utilizada pelo autor do livro Os Aleluias, Ruy Llera Blanes, assume outras direcções.

Tendo como enfoque específico o fenómeno do movimento evangélico cigano na Península Ibérica - nomeadamente a Igreja Evangélica de Filadélfia -, a monografia investiga os contextos em que música, religião, identidades e memória histórica se entrelaçam e onde as práticas musicais assumem relevância singular e explicativa enquanto promotoras "de sentidos de espaço e tempo, de momento e lugar" dentro de um contexto de "identidades diaspóricas" (p. 59). Embora o conceito de diáspora, associado a "terrenos ciganos", tivesse 
talvez necessitado de uma análise mais crítica, do ponto de vista histórico e identitário, dada a complexidade problemática da discussão teórica sobre diáspora como "prática social" - cf., entre outros, Rogers Brubaker, "The 'diaspora' diaspora", Ethnic and Racial Studies, 28 (1), pp. 1-19, 2005; Martin Sökefeld, "Mobilizing in transnational space: a social movement approach to the formation of diaspora", Global Networks, 6 (3), pp. 265-284, 2006; Kachig Tölölyan, "Rethinking diaspora(s): stateless power in the transnational moment", Diaspora, 5, pp. 3-36, 1996 -, o autor propõe uma interpretação interessante ao enfatizar a dimensão musical, no seio do contexto evangélico, como "agente de ciganidade" (p. 61). Finalmente, não é por acaso que neste trabalho o antropólogo adoptou uma metodologia bissituada, de modo a tornar evidente a necessidade da complementaridade entre o terreno de investigação português (Lisboa) e o terreno espanhol (Madrid).

Trata-se de uma pesquisa que se insere na linha de intersecção entre as abordagens teóricas da antropologia de comunidades ciganas e da antropologia das religiões, embora a argumentação seja definitivamente mais centrada na análise dos cultos religiosos. De resto, os conteúdos dos últimos três capítulos demonstram a centralidade da "vertente experiencial, performativa e participativa" (p. 137) do culto, descrita através de práticas e ideologias que se destacam por colocarem o acento em questões fundamentais às quais o autor procura dar resposta ao longo do texto - entre elas, as da marginalidade, da mobilidade/diáspora, da modernidade cigana, da reivindicação identitária, do reconhecimento político e social.

Patrick Williams, num artigo de 1995 ("Quesiti per lo studio del movimento pentecostale tra gli Zingari”, La Ricerca Folklorica, 31, pp. 133-138), interrogava-se relativamente aos "quesitos" que o nascimento e o crescimento do próprio movimento pen- tecostal cigano colocam aos comentadores ou aos investigadores; de facto, o fenómeno obriga a ampliar o olhar explicativo para moldar leituras fechadas, dirigidas, por exemplo, à análise de uma eventual crise que a sociedade cigana estaria a enfrentar e que justificaria o sucesso do movimento (p. 133).

Com efeito, o autor do presente livro oferece uma leitura que lida com as transformações estruturais que, ao longo do século XX, os ciganos da Península Ibérica experienciaram, passando "de um nomadismo rural a uma vida nos subúrbios multiculturais das principais urbes" (p. 18) - um argumento entre outros possíveis. O conceito da "marginalidade" social que perpassa os capítulos do livro, explícita ou implicitamente, é explorado de tal forma que, embora permanecendo "na sua essência o mesmo” (p. 32), se reconfigura a partir de um novo contexto histórico, social, cultural, experiencial. A proposta é de interpretá-lo como uma "estratégia" relacional e identitária, no sentido da reinvenção de uma nova "ciganidade" através do uso da própria marginalidade, a qual se tornaria um instrumento que inverte a polaridade entre a vitimização do sujeito e a reivindicação étnica activa.

"O ‘Senhor' tem substituído os 'Gadjé’”, dizia Patrick Williams (no artigo referido, p. 135, tradução minha) para colocar o processo de "transformação", vindo da adesão ao movimento pentecostal, na análise do cruzamento entre as dimensões relacionais internas e externas aos próprios grupos ciganos; isto é, perguntamo-nos se as dinâmicas do evangelismo cigano se colocam nas relações entre ciganos ou naquelas entre ciganos e não-ciganos, ou eventualmente nas duas, e com que características, inclusive a reivindicação, ou não, de visibilidade e "emergência” social, religiosa e até política.

Talvez seja neste ponto que a proposta etnográfica de Os Aleluias resulte, de certa forma, carenciada de uma análise mais 
dialéctica, que seja capaz de actualizar o diálogo relacional, justamente entre as famílias ciganas com as quais o antropólogo trabalhou e os espaços experienciais por elas vivenciados e construídos na contínua "negociação" social e cultural com o "mundo" dos não-ciganos. Embora relativa a um contexto histórico e cultural específico, o das famílias francesas manouches, a etnografia Nous, on n'en parle pas, de Patrick Williams (Ministère de la Culture et de la Francophonie/Maison des sciences de l'homme, 1993), ao analisar a dimensão do "silêncio" e do "rumor", e ao perguntar-se

Benoît de l'Estoile

LE GOÛT DES AUTRES:

DE L'EXPOSITION COLONIALE

AUX ARTS PREMIERS

Paris, Flammarion, 2007, 454 páginas.

Nos últimos vinte anos, a situação dos grandes museus etnográficos franceses alimentou acesos debates. O livro de Benoît de l'Estoile foi publicado um ano após a inauguração, em Junho de 2006, do Musée du Quai Branly, constituído a partir das colecções etnográficas exóticas do Musée de l'Homme. Numa língua sempre clara, integrando referências bibliográficas cosmopolitas, estas 454 páginas notavelmente documentadas incluem úteis índices de pessoas, de temas, de museus e exposições uma prática que ainda não é geral na edição francesa de ciências sociais; deplora-se, em contrapartida, a ausência de uma bibliografia recapitulativa. A partir das questões suscitadas pela elaboração do Musée du Quay Branly (nome ocultando a polémica designação inicial de Musée des Arts Premiers), se o advento e a adesão consistente dos manouches ao movimento pentecostal não terá intervindo na relação "silenciosa" entre manouches, oferece um ponto de vista interessante para a exploração de aspectos que talvez tenham sido menos aprofundados por Ruy Llera Blanes, como o da construção social do movimento religioso da Igreja de Filadélfia, que nos indica quão constitutivas do mesmo são as redes ciganas de pertença e sociabilidade familiar e parental.

\section{Micol Brazzabeni}

CRIA, bolseira FCT aborda-se problemas mais amplos: o sentido dos "museus dos Outros" no mundo pós-colonial; o museu enquanto catalisador de uma antropologia do "goût des Autres" (alusão a um filme de Agnès Jaoui centrado nas difíceis relações, no quotidiano, entre adeptos de gostos estéticos diferentes), das "nossas concepções da alteridade e das suas transformações” (p. 20). É de notar que, como o autor aliás admite, a dicotomia museu dos Outros/museu de Nós é demasiado esquemática, como se vê com o Museu Nacional de Etnologia de Lisboa.

Procurando um distanciamento, a análise procede por historicização e comparação. A primeira parte mostra como, entre as duas guerras mundiais, três tipos de discursos (evolucionista, diferencialista, primitivista) se entrelaçam, nomeadamente na Exposition Coloniale de 1931, resultando num universalismo plural consagrado em 1937 pela inauguração do Musée de l'Homme e o "triunfo da etnologia" enquanto detentora da autoridade científica sobre os objectos dos Outros. O projecto colonialista combina-se com um reconhecimento da diversidade 